\title{
COVID-19 Pandemic: Cardiovascular Complications and Future Implications
}

\author{
Dhrubajyoti Bandyopadhyay ${ }^{1} \cdot$ Tauseef Akhtar $^{2} \cdot$ Adrija Hajra $^{3}$ (D) Manasvi Gupta ${ }^{4} \cdot$ Avash Das $^{5}$. \\ Sandipan Chakraborty ${ }^{6} \cdot$ Ipsita Pal $^{7} \cdot$ Neelkumar Patel $^{8} \cdot$ Birendra Amgai $^{8} \cdot$ Raktim K. Ghosh $^{9} \cdot$ Gregg C. Fonarow $^{10}$. \\ Carl J. Lavie ${ }^{11} \cdot$ Srihari S. Naidu ${ }^{12}$
}

Published online: 23 June 2020

(c) Springer Nature Switzerland AG 2020

\begin{abstract}
Coronavirus disease 2019 (COVID-19), caused by severe acute respiratory syndrome coronavirus 2 (SARS-CoV-2), is now a global pandemic with the highest number of affected individuals in the modern era. Not only is the infection inflicting significant morbidity and mortality, but there has also been a significant strain to the health care system and the economy. COVID-19 typically presents as viral pneumonia, occasionally leading to acute respiratory distress syndrome (ARDS) and death. However, emerging evidence suggests that it has a significant impact on the cardiovascular (CV) system by direct myocardial damage, severe systemic inflammatory response, hypoxia, right heart strain secondary to ARDS and lung injury, and plaque rupture secondary to inflammation. Primary cardiac manifestations include acute myocarditis, myocardial infarction, arrhythmia, and abnormal clotting. Several consensus documents have been released to help manage CV disease during this pandemic. In this review, we summarize key cardiac manifestations, their management, and future implications.
\end{abstract}

\section{Key Points}

Coronavirus disease 2019 (COVID-19) has a significant impact on the cardiovascular (CV) system, both directly and indirectly.

COVID-19 infection utilizes the angiotensin-converting enzyme 2 receptor for entry into the cell

Infection can cause several CV syndromes, including myocardial damage, acute coronary syndrome, and arrhythmia.

COVID-19 can result in hypercoagulability, resulting in venous thromboembolism and pulmonary embolism, with consequent right ventricular dysfunction or failure.

Clinicians should also be aware of the CV effects of drugs used for COVID-19 treatment.

Dhrubajyoti Bandyopadhyay, Adrija Hajra and Srihari S. Naidu contributed equally.

Adrija Hajra

adrija847@gmail.com

Extended author information available on the last page of the article

\section{Introduction}

Coronavirus disease 2019 (COVID-19) is a rapidly spreading novel infectious disease of the human respiratory system caused by a newly discovered enveloped RNA $\beta$-coronavirus named severe acute respiratory syndrome coronavirus 2 (SARS-CoV-2) [1]. Coronavirus has been responsible for previous epidemics, such as SARS-CoV and the Middle East Respiratory Syndrome (MERS)-CoV (Table 1). Since diagnosis of the index case, linked to the seafood and wet animal wholesale market in Wuhan, Hubei Province, China, in December 2019 [2], the disease has spread to involve more than 200 countries. As of 29 May 2020, the total number of cases in the US was $1,719,827$, including 101,711 deaths [3]. The first case of COVID-19 was reported in the US on 30 January 2020, and, since then, more than 1.5 million cases have been diagnosed. Given the substantial morbidity and mortality caused by this disease within a short timeframe and the high rate of human-to-human transmission, the World Health Organization (WHO) declared COVID-19 a pandemic on 11 March 2020 [4].

It is noteworthy that COVID-19 has a lower fatality rate than the previous outbreak of SARS, but has a more remarkable capacity to spread quickly, thus making it an 
Table 1 Timeline of coronavirus infection affecting humans

1965: Tyrrell and Bynoe1 identified a virus named B814

2002-2003: Severe acute respiratory syndrome (SARS)

2012: Middle East Respiratory Syndrome

2019-2020: Covid-19 (the illness caused by SARS-CoV-2 infection)

First reported case to the WHO Country Office in China on 31 December 2019

On 20 January 2020, the CDC confirmed a positive test for 2019-nCoV, by rRT-PCR, in an individual in the US

In a meeting on 30 January 2020, per the International Health Regulations (2005), the WHO declared the outbreak was a Public Health Emergency of International Concern

On 11 February 2020, the WHO Director-General announced that the disease caused by this new CoV was 'COVID-19'

WHO raised the threat to the CoV epidemic to the 'very high' level on 28 February 2020

On 11 March 2020 WHO declared COVID-19 a pandemic

$C D C$ Centers for Disease Control and Prevention, $C o V$ coronavirus, $r R T$-PCR real-time reverse-transcriptase-polymerase-chain-reaction, $W H O$ World Health Organization

ideal infection to result in a pandemic. Our understanding of this disease is still evolving; however, a substantial amount of data has emerged recently indicating not just pulmonary involvement but significant involvement, both direct and indirect, of the cardiovascular (CV) system [5-7]. Interestingly, cardiac complications are not only prevalent but also signify a poor prognosis and may develop late in the course of more severe cases of the disease. In this review, we briefly discuss the pathogenesis, clinical manifestations, and diagnosis of COVID-19, with an emphasis on cardiac involvement, management strategies, and potential future implications, understanding that this is an area where information is accruing and changing rapidly.

\section{Pathogenesis}

The lung is the principal organ affected in the early stages of COVID-19. The virus utilizes the angiotensin-converting enzyme 2 (ACE2) receptor, abundant in the lower respiratory tract, for entry into the cells. Importantly, ACE2 is also expressed in the heart, intestinal epithelium, vascular endothelium, and the kidneys, making all of these organs potential targets [4]. The $S$-glycoprotein receptor located on the surface of the virus consists of two subunits, S1 and S2, which attach to the ACE2 receptor $[5,6]$. S1 determines the virus host range and cellular tropism, whereas $\mathrm{S} 2$ mediates fusion of the virus-cell membrane followed by the release of viral RNA into the cytoplasm. This is followed by the translation of new viral particles, with subsequent release to infect other cells $[7,8]$.

After the initial infection, the acute disease progression can be divided into three distinct phases (early infection phase, pulmonary phase, and a hyperinflammation phase) with significant overlap [9-11]. The hyperinflammation stage is characterized by a cytokine storm, leading to immune-mediated injuries to distant organs [11]. Studies have demonstrated significant elevation of inflammatory markers, including interleukin (IL)-6, IL-2, IL-7, tumor necrosis factor (TNF)- $\alpha$, interferon-inducible protein (IP)10, monocyte chemoattractant protein (MCP)-1, macrophage inflammatory protein (MIP)-1 $\alpha$, granulocyte colony stimulating factor (G-CSF), C-reactive protein (CRP), procalcitonin, and ferritin [12-17].

The exact pathogenesis of cardiac involvement is not entirely clear. Increased cardiac biomarkers, including troponin $\mathrm{T}$, have been shown to be linearly correlated with inflammatory markers, indicating that myocardial injury is likely related to underlying inflammation [18]. Several mechanisms of cardiac damage are likely at play, including direct myocardial damage by the virus itself, hypoxic injury mediated by respiratory failure, indirect injury mediated by cytokines secondary to systemic inflammatory response, myocardial infarction (MI) due to plaque rupture secondary to systemic inflammation, the prothrombotic state produced by severe systemic inflammation, and ischemia from myocardial supply-demand mismatch (Fig. 1). ACE2 receptor-mediated direct cardiac injury also remains a possibility. ACE2 receptors are expressed in cardiac pericytes and endothelial cells, and animal data suggest that their direct dysfunction secondary to viral infection or secondary inflammation may precipitate MI $[19,20]$.

\section{Clinical Manifestations}

The median incubation period of COVID-19 has been determined to be 5.7 days, with $97.5 \%$ of patients developing symptoms within 12.5 days of exposure [21]. The most common symptoms are non-specific, including fever (88\%), fatigue $(70 \%)$, dry cough $(67.7 \%)$, anorexia $(40 \%)$, and myalgia (35\%). Anosmia and dysgeusia have also been 


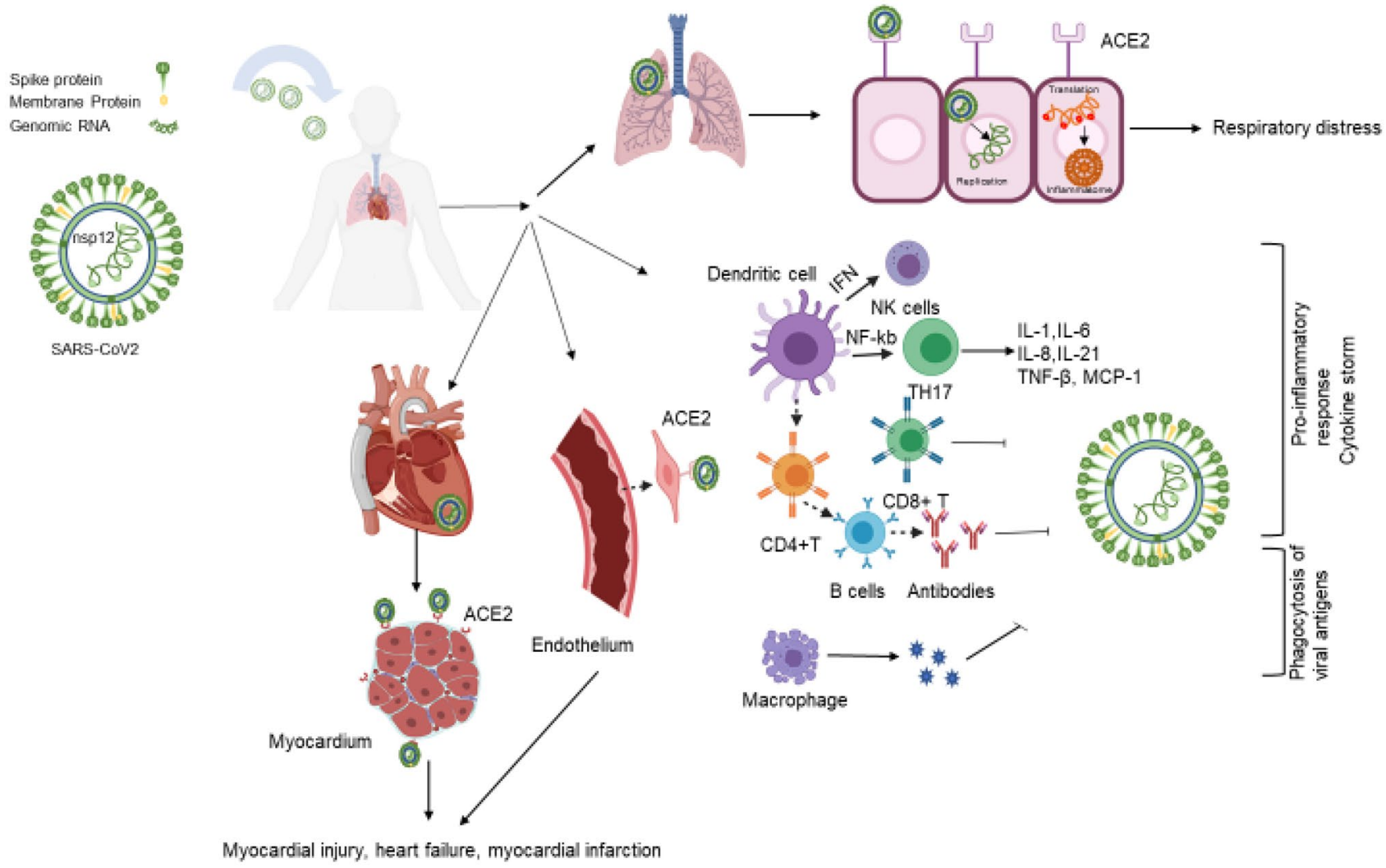

Fig. 1 Schematic representation of the COVID-19 structure and route of infection. This figure describes the structure of the SARS-CoV-2. In the respiratory system, the virus spike protein binds with the ACE2 receptor in respiratory epithelial cells and internalizes and forms a membrane fusion complex, which causes the release of the viral RNA into the host cell and results in respiratory infection. Through different pathways, the virus induces the proinflammatory response by induction of T- and B-cells and synthesis of type I IFNs, which limit

reported as notable and somewhat specific symptoms. Upper respiratory tract symptoms such as rhinorrhea are conspicuously less common. Gastrointestinal symptoms, including nausea and diarrhea $[22,23]$ are also less common.

The initial experience from China suggests that approximately $81 \%$ of infected patients experience mild disease, with severe disease developing in $14 \%$. Pneumonia with acute respiratory distress syndrome (ARDS) is the most common severe manifestation. Critical illness with septic shock and multi-organ dysfunction has been reported in 5\% of patients [13].

\subsection{Cardiac Manifestations}

As previously discussed, cardiac injury is a common problem associated with COVID-19 [24]. Acute coronary syndrome (ACS), arrhythmias, and blood pressure fluctuations have been reported to occur, in addition to cardiac dysfunction. The incidence of arrhythmia has not been clearly the spread of the virus and cause a cytokine storm, while induction of the macrophage causes ingestion of the viral antigen [this image is generated with the help of Biorender]. SARS-CoV-2 severe acute respiratory syndrome coronavirus $2, A C E 2$ angiotensin converting enzyme 2, IFNs interferons, $N K$ natural killer, TH17 T-helper 17, IL interleukin, $T N F$ tumor necrosis factor, $M C P$ monocyte chemoattractant protein

reported, although it is expected to be more frequently seen in critically ill patients; these include tachyarrhythmia, bradyarrhythmia, and asystole [16, 25]. In a study conducted in Wuhan, cardiac conditions, including heart failure (HF), contributed to $40 \%$ of the mortality, either acting alone or in conjunction with respiratory failure [15].

\section{Cardiovascular Effects}

Previous viral epidemics have been associated with a significant increase in the incidence of myocarditis, cardiomyopathy, HF, MI, arrhythmias, and sudden cardiac death [26-28]. It was therefore not unexpected to see a higher incidence of $\mathrm{CV}$ events in those infected with COVID-19. On the other hand, the presence of pre-existing cardiac conditions appears to increase the chance of complications, including death, in COVID-19 patients. As reported in a meta-analysis of patients admitted with COVID-19, the incidence of CV 
disease (CVD) was $16.4 \%$ in non-intensive care unit (ICU) patients, and three times higher in those requiring the ICU [29]. In the following sections, we highlight various baseline $\mathrm{CV}$ comorbidities and disorders that have been reported to date with COVID-19 (Table 2).

\subsection{Myocardial Damage}

Cardiotropic viruses directly attack cardiac cells at the initial phase, followed by a secondary inflammatory response that can lead to further cardiac damage. It is likely that coronavirus is following a similar pathway. Indeed, the ACE2 receptor plays a role in the direct cardiac damage, as well as vascular involvement in COVID-19 infection. In autopsies from the SARS outbreak in $2002,35 \%$ of heart samples revealed the presence of viral RNA in the myocardium, and it was associated with reduced ACE2 expression. It is believed SARS-CoV-2 may share the same mechanism, with direct cardiac muscle damage playing a role in both the myocarditis and HF in COVID-19-infected individuals. Cardiac muscle involvement has been evident by increased cardiac biomarkers in a sizable portion of patients [42]. Additionally, autopsy studies of COVID-19 have demonstrated the presence of mononuclear infiltrate in the myocardium, with related cardiomyocyte necrosis [43]. Finally, acute lung injury and ARDS result in right heart strain, with right ventricular (RV) dilation and dysfunction, and high positive end expiratory pressure (PEEP) use while on ventilation can also worsen cardiac function [44].

Many studies have shown poorer outcomes, including mortality, in patients with elevated biomarkers (such as cardiac troponin, creatinine kinase, pro-brain natriuretic peptide [BNP]) in COVID-19-related ARDS [45, 46]. In a prospective cohort study of 179 patients with COVID-19 pneumonia, a cardiac troponin I level of $\geq 0.05 \mathrm{ng} / \mathrm{mL}$ was found to be strongly associated with increased mortality (hazard ratio [HR] 4.077, 95\% confidence interval [CI] 1.166-14.253; $p<0.001$ ) [47]. In another study of 273 patients, cardiac biomarkers (N-terminal [NT] pro-BNP, cardiac troponin, and myoglobin) were significantly higher in severe and critical cases compared with mild cases [48]. Another study aimed at correlating the change in troponin levels with the progression of COVID-19 disease, and showed that $37.5 \%$ of patients with normal troponin at admission had a rise in troponin during hospitalization, which peaked in the week before demise [49]. A meta-analysis of 341 patients in China confirmed the findings of these studies, reinforcing the importance of troponin measurement at admission and/or during hospitalization to determine the severity of the disease.

Importantly, troponin can be elevated in COVID patients with underlying renal impairment [42]. In this setting, elevations of other cardiac biomarkers will be more reliable as an indicator of underlying cardiac injury. Zhou et al. and $\mathrm{Li}$ et al. have described increased levels of creatine kinase-myocardial band (CK-MB), myoglobin, and NTpro-BNP in COVID patients, which also correlated with the severity of disease [50, 51].

EKG and echocardiographic findings, in conjunction with biomarker elevation, help diagnose and predict prognosis in COVID-19 patients with cardiac involvement. Notably, data on the correlation between biomarkers, clinical manifestations and echocardiographic findings are lacking, and further study of this relationship may ultimately help in early risk stratification [52]. Although case reports of myocarditis in COVID-19 patients exist, it is unclear whether the myocarditis is induced by the virus directly or results from an inflammatory response [53]. A case of myopericarditis complicated by cardiac tamponade was also reported in the literature [54]. Isolated hemorrhagic pericardial effusion with tamponade without the features of myocarditis has also been demonstrated [55]. Recently, two cases have been reported with apparent Takotsubo syndrome in the setting of COVID infection [56, 57].

Although cardiac involvement usually occurs later in the course of COVID-19, acute HF secondary to myocardial involvement or previously existing cardiac disease could be the presenting symptoms in COVID-19 infection in almost one-quarter of patients. The management of myocardial dysfunction in COVID-19 leading to HF is similar to other forms of HF. Optimization of fluid balance, monitoring of electrolytes and renal function, and early use of the cardiac catheterization laboratory and invasive monitoring all play important roles in managing COVID patients with HF [58].

\subsection{Coronary Ischemia/Infarction}

Coronary involvement and ischemia have been seen, including ST-elevation myocardial infarction (STEMI) and nonST-elevation myocardial infarction (NSTEMI), with several mechanisms explaining coronary artery involvement. As ACE2 is expressed in vascular endothelial cells, direct viral infection can lead to plaque instability and type $1 \mathrm{MI}$. Plaque instability and rupture may also result from the severe systemic inflammatory response in the third phase of the disease. COVID-19 can additionally precipitate type II MI by demand ischemia as patients get sicker. Hypoxia secondary to lung involvement, and fever and tachycardia secondary to sepsis, further worsen the cardiac function. Coronary artery involvement can further be produced by a microangiopathy that has also been described. Such small vessel involvement can be due to systemic vasculitis or to microembolization from ACS or disseminated hypercoagulability impairing blood flow [42].

The management of STEMI has been particularly difficult. Currently, multiple factors have been sources of delay for a primary percutaneous coronary intervention (PCI) approach, 


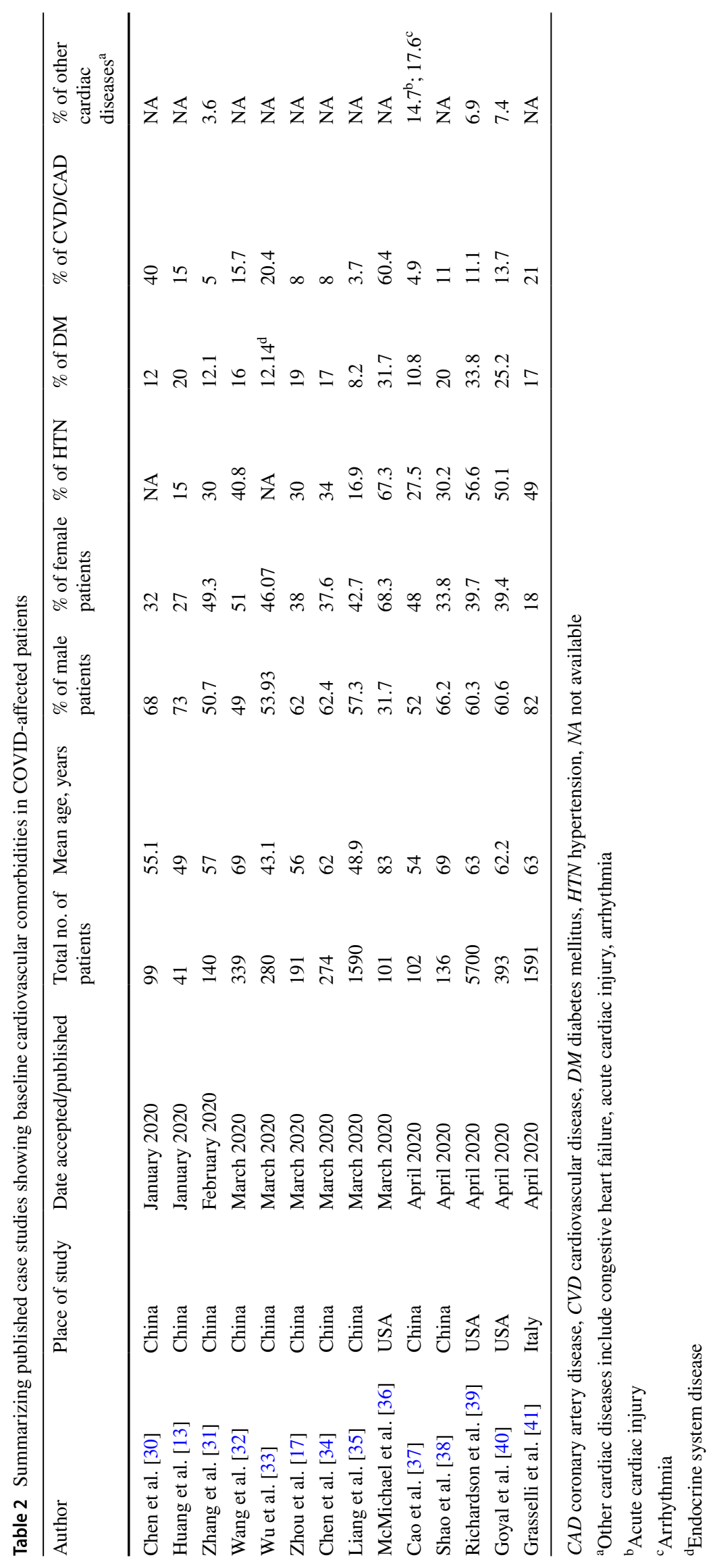


including determining whether STEMI or COVID is the primary problem, and deciphering mimickers of STEMI, such as Takotsubo cardiomyopathy, myocarditis, RV failure, or massive pulmonary embolism (PE). In the emergency department, screening for COVID infection may take some time, and, within the catheterization laboratory, additional time is needed for donning and doffing personal protective equipment (PPE). In addition, redeployment of staff has resulted in shortages to team availability. From a procedure room standpoint, catheterization laboratories are positive pressure rooms with a significantly higher risk of aerosolization, and therefore some have been converted to negative pressure rooms, while others must be fitted with high efficiency particulate air (HEPA) filters. In addition, specific protocols for anesthesia, emergent intubation, and protection of staff and equipment have been implemented, all of which add time to the care of these patients.

A small study evaluating primary PCI in seven patients presenting with STEMI calculated the time from onset of symptoms to medical contact to be a median of $318 \mathrm{~min}$, compared with a median of 82.5-91.5 min recorded in the previous year. Similarly, the door-to-device time was almost 30 min longer, at a median of $110 \mathrm{~min}$, compared with a median of $84.9 \mathrm{~min}$ in the previous year [59]. When put in the context of existing data on door-to-balloon (D2B) time and $\mathrm{CV}$ outcomes, while 60-90 min estimates the absolute risk reduction of 1 -year mortality at $2.4 \%$, the odds worsen when this time increases to $90-120 \mathrm{~min}$. In the same study, an incremental increase in the D2B time by $1 \mathrm{~h}$ was associated with a $64 \%$ increase in 1-year mortality (HR 1.90, 95\% CI 1.51-2.39; $p<0.001)$ [60].

According to recent statements by the American College of Cardiology (ACC) Interventional Council and Society for Cardiovascular Angiography and Intervention (SCAI) regarding the management of STEMI during the COVID19 pandemic, primary PCI should remain the standard in these patients, with fibrinolytic therapy reserved for patients with relative contraindications or those with severe bilateral COVID pneumonia (PNR) or ARDS, given the poor overall prognosis (Fig. 2) [61]. NSTEMI patients with suspected or confirmed COVID-19 should be managed by aggressive medical management until the test comes back, and then risk stratification. High-risk patients or hemodynamically unstable patients should be managed by early invasive strategy $(<24 \mathrm{~h})$, as in all patients with NSTEMI. A non-invasive or medical approach would be best for low-risk patients.

Coronary computed tomography (CT) angiography may be considered for risk stratification [61], and has the added advantage of evaluating the lung parenchyma for signs of COVID pneumonia or other etiologies of decompensation, such as PE with RV failure. This strategy has been adopted at some institutions for patients in whom there are both pulmonary and cardiac manifestations, especially in the setting of fever.

\subsection{Arrhythmias}

The incidence of arrhythmia is currently unknown in COVID-19 patients, with preliminary data suggesting an incidence of $16.7 \%$ among hospitalized patients and $44.4 \%$ of ICU admissions [16]. Both ventricular and atrial arrhythmias have been seen, in addition to sinus tachycardia due to clinical decompensation, fever, or sepsis. The cause of arrhythmia could be myocarditis, hypoxia, or electrolyte derangement seen in these patients, and in many cases may be reactive. Management of these arrhythmias are largely supportive, with control of the underlying clinical condition, electrolyte repletion, and pharmacologic antiarrhythmic therapy.

Specific mention should be made regarding drugs to treat COVID-19 and the potential for pro-arrhythmia. Although data on outcomes with hydroxychloroquine are not available, it is widely used in hospitals for critical patients. The drug is a known inhibitor of the potassium channel Kv11.1 present in the heart, potentially increasing the QTc interval and predisposing the patient to fatal ventricular tachyarrhythmias (torsades de point). In the setting of a very long half-life of 40 days, this adverse effect is rarely seen in clinical practice in patients routinely treated for malaria and rheumatological conditions such as systemic lupus erythematosus [62, 63], but the incidence alongside COVID-19, especially in severe cases, remains unclear. According to the recommendations from the Heart Rhythm Society released recently in collaboration with the ACC and AHA, hydroxychloroquine use must be closely monitored in certain patient groups. These include individuals with a known history of long QT syndrome, those with deranged renal function, those with electrolyte abnormalities such as hypokalemia and hypomagnesemia, and those prescribed other QTc-prolonging drugs [64]. When administered in combination with azithromycin, which is also known to prolong the QTc interval, dose adjustments may be necessary [65]. Recently, the US FDA has mentioned the risk of this combination therapy [66].

Arrhythmias leading to cardiac arrest deserve special mention. Cardiopulmonary resuscitation (CPR) with chest compressions is very high risk for aerosolization of virus, and a minimum number of caregivers should be inside the room, with full PPE. To minimize prolonged exposure, mechanical CPR devices may be considered, and all attempts should be made to prioritize immediate intubation into a closed circuit by anesthesiologists so that the duration of any aerosolization is kept to a minimum. While waiting for intubation, bag/mask ventilation with filter is recommended. The choice of tools for intubation should be determined by the expected success rate, with preference given to devices with the highest first-pass rate. Video laryngoscopy should be used where possible to ensure quick and effective airway management, and minimal to no disconnections in the closed-circuit should be the goal [67]. 


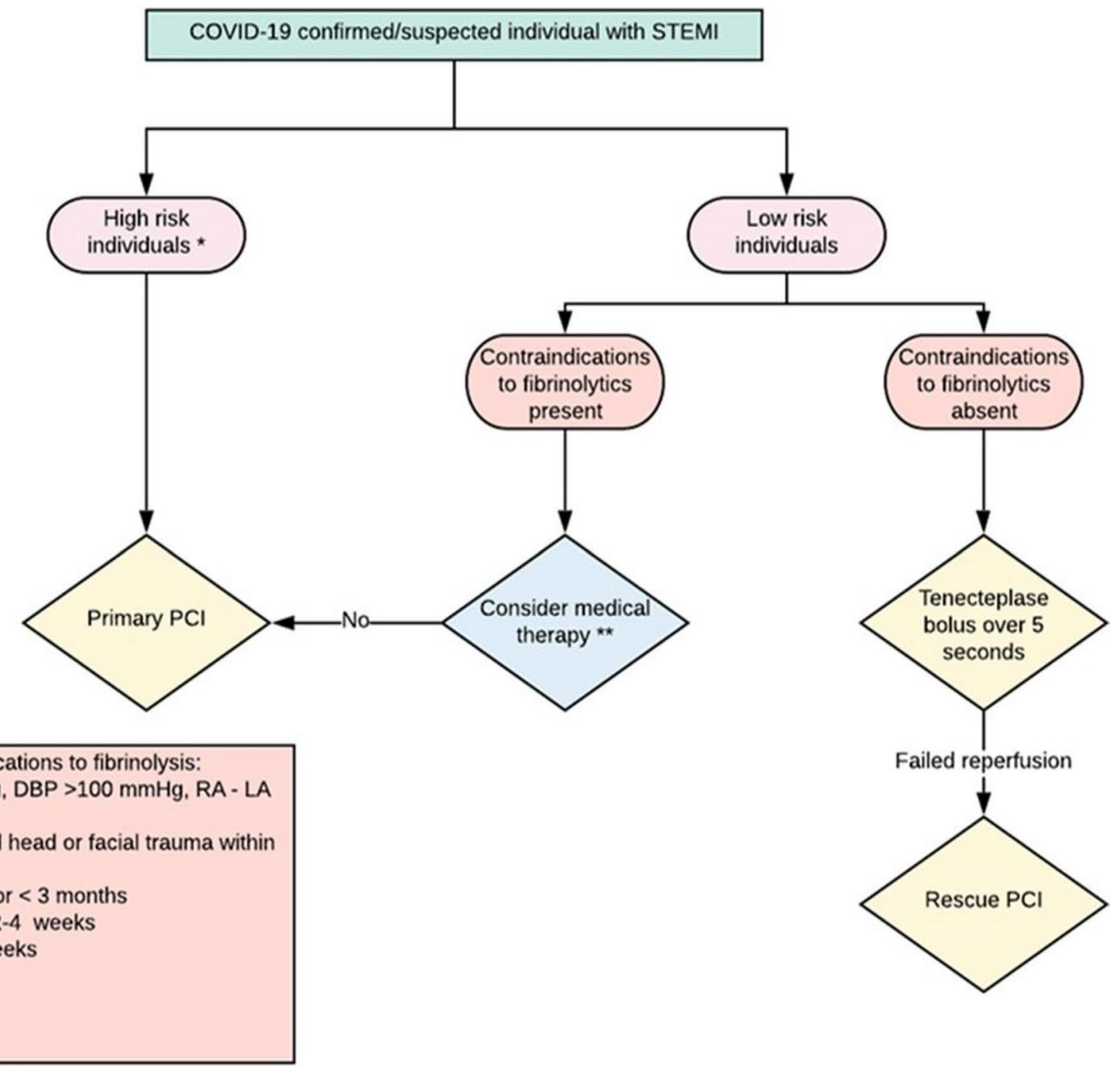

Fig. 2 Management of STEMI in COVID-19 confirmed/suspected patients. $A C E i$ angiotensin-converting enzyme inhibitor, $B P$ blood pressure, $C P R$ cardiopulmonary resuscitation, $D B P$ diastolic blood pressure, $G I$ gastrointestinal, $G U$ genitourinary, $H / O$ history of, $H R$ heart rate, $I C H$ intracranial hemorrhage, $L A$ left arm, $P C I$ percutane-

\subsection{Venous Thromboembolism}

An increased risk of blood clot formation resulting from hypercoagulability has been previously noted with SARS and MERS [68]. Similarly, COVID-19 has been associated with a hypercoagulable state. Dysfunction of endothelial cells induced by infection results in excess thrombin generation and fibrinolysis shutdown. The hypoxia found in severe COVID-19 can also stimulate thrombosis through increasing blood viscosity. A hypoxia-inducible transcription factor-dependent signaling pathway also plays a role in increasing the coagulability of the blood [69]. A study by Panigada et al. showed an increased risk of venous ous coronary intervention, $R A$ right arm, $S B P$ systolic blood pressure, STEMI ST-elevation myocardial infarction. *High risk individuals: 1 . HR $>100 / \mathrm{min}$ and SBP $<100 \mathrm{~mm}$ of $\mathrm{Hg}, 2$. pulmonary edema, 3. signs of shock,4. CPR required. **Medical therapy: 1. antiplatelet, 2. anticoagulation, 3. high intensity statin, 4 . beta blocker/ACEi

thrombosis in COVID-19-affected individuals [70]. One study involving 184 patients showed CT angiography and/ or ultrasonography confirmed venous thromboembolism (VTE) in $27 \%$ of patients and arterial thrombotic events in $3.7 \%$ of patients. PE was the most frequent thrombotic complication and may be massive with significant RV failure [71]. The diagnosis of VTE and PE in COVID patients is challenging. The International Society on Thrombosis and Hemostasis (ISTH) advocates the use of laboratory tests, including D-dimers, prothrombin time, and platelet count, to stratify patients at risk of increased blood clot formation [72]; however, elevated D-dimer levels are not specific to the diagnosis of VTE. If only a high D-dimer 
level is relied on for diagnosis, it will unnecessarily increase the utilization of CT angiography for infected patients, without much benefit. In addition, it may worsen kidney function due to contrast use in the setting of poor cardiac output and hypoxia from COVID-19 [73]. Maintaining isolation while doing the tests is also another hurdle for hospitals. Echocardiogram may aid in the diagnosis of large PE by finding isolated RV dilation or failure, or a saddle PE, although it may be difficult to visualize [74].

Prophylaxis with low-molecular-weight heparin (LMWH) is recommended for every patient, if not contraindicated [72]. In a study involving 449 patients with severe COVID-19, anticoagulant therapy, mainly with LMWH, was associated with lower mortality in patients with markedly elevated D-dimer [75]. The use of unfractionated heparin may be superior in critically ill patients with underlying renal failure, which is a contraindication to LMWH. Interestingly, in vivo models of coronavirus infection have shown that administration of unfractionated heparin functions as a decoy receptor, reducing viral infectivity and potentially augmenting viral clearance [76]. Heparin also has anti-inflammatory effects, reduces myocardial inflammation, and has shown antiviral effects in animal models [77]. Tissue plasminogen activator (TPA) has shown transient improvement in a case series but there is still a lack of data regarding the safety of use in this setting. Furthermore, there have been no data on the adequate dose of TPA [78].

Direct-acting oral anticoagulants (DOACs) can also be considered in the treatment of thromboembolism in COVID19 infection. However, drug interactions between DOAC and antiviral treatments, as well as dosing concerns in the setting of changing kidney function, need to be considered before prescribing these drugs [79]. Asakura et al. have proposed the use of nafamostat, a synthetic serine protease inhibitor, as a short-acting anticoagulant with antiviral properties, along with heparin, in COVID patients; more data are required regarding the efficacy of this agent [80]. A study has shown an increased incidence of VTE even in anticoagulated patients, but the small sample size and retrospective nature are two limitations of that study [81]. Recently published clinical data have suggested that systemic anticoagulation may be associated with positive outcomes among patients hospitalized with COVID-19, but that study has some limitations, including its observational nature and unobserved confounding factors [82].

\section{Antihypertensive Medications}

It is estimated that $15-30 \%$ of COVID-19 patients have hypertension (HTN) [16]. Indeed, a meta-analysis $(n=46,248)$ including eight studies from China demonstrated that the most common cardiac comorbidity was HTN (17 $\pm 7 \%, 95 \%$ CI 14-22\%) [83]. ACE2 receptor expression is similar in adipose and non-adipose tissues, but as obese individuals have more adipose tissue in the body, they may have an increased number of receptors. Although some have reported obesity to be a risk factor for COVID infection, more data are required to see if obese individuals are indeed more vulnerable [84].

Given the prevalent use of ACE inhibitors (ACEI) and angiotensin receptor blockers (ARBs), and the predominant role of ACE2 receptors in the disease pathogenesis, there has been some concern surrounding the use of these medications in COVID-19 patients. Animal data have supported that chronic use of ARBs elevates ACE2 receptor expression, and elevated ACE2 expression has potential protective $\mathrm{CV}$ effects [85]. Zhang et al. recently published a retrospective, multicenter study including 1128 adult patients with COVID-19 and found a lower risk of all-cause mortality with inpatient use of ACEIs/ARBs compared with ACEIs/ ARBs non-users [86]. Jarcho et al. have highlighted three more recently published studies, showing no evidence of increased risk of infection or inpatient mortality in COVIDaffected patients who continued on these medications [87]. Another recent study has shown similar confirmation [88]. Based on available data, most of the major society guidelines have recommended against stopping ACEIs/ARBs in patients already taking these medications, or initiating these medications in newly diagnosed patients [89-91].

\section{Experimental COVID Drug Use and Cardiovascular Adverse effects}

A host of therapeutic agents have been employed to treat patients with COVID-19, however a detailed review of these is beyond the scope of this review. We focus on the most promising drugs that have been repurposed and used to treat this disease, emphasizing the $\mathrm{CV}$ adverse effects of these therapies and the known strategies to counter them. Among the treatments employed, chloroquine and hydroxychloroquine, antiretrovirals (lopinavir and ritonavir), ribavarin, remdesivir, corticosteroids, anticytokine agents (IL-6 inhibitors), and immunoglobulin therapy (convalescent plasma) have been prominent [92]. Chloroquine and hydroxychloroquine have been used to treat patients with COVID-19 in small randomized clinical trials and are postulated to work by blocking viral entry into cells through endosomal trafficking and by exerting an immunomodulatory effect through cytokine attenuation. Both agents can cause QTc prolongation, as previously discussed, which can be aggravated by concomitant use of azithromycin, a macrolide antibiotic, and other fluoroquinolones. Baseline electrocardiography is recommended in patients to evaluate for prolonged QTc in specific high-risk populations, as previously discussed. Serial electrocardiography 
in critically ill patients following the initiation of these medications is useful to monitor [65]. A detailed treatment workflow with hydroxychloroquine is provided in Fig. 3. Lopinavir and ritonavir also have the potential to cause QTc prolongation [93]. Ribavirin has the potential to cause hemolytic anemia in high doses [94], which can also increase CVD risk and hemodynamic instability. Table 3 summarizes the possible CV adverse effects of experimental therapies.

\section{Future Complications and Implications}

Apart from complications during the active phase of infection, as described herein, long-term sequelae of the disease remain a possibility despite complete viral clearance. Previous epidemics from similar viruses can be informative in providing some clues for the long-term $\mathrm{CV}$ complications of COVID-19. For example, the 2002 SARS epidemic caused metabolic alterations through an increase in the level of phosphatidylinositol and lysophosphatidylinositol in recovered SARS patients in comparison with healthy volunteers [95]. This metabolic change was subsequently associated with hyperlipidemia and also with impaired glucose metabolism. Multiple studies have reported avascular necrosis as a long-term complication from the corticosteroids prescribed to SARS patients [96, 97]. However, the mechanism leading to these metabolic changes as a result of the viral infection remains unknown. Osteonecrosis is independently associated with an increased risk of adverse CV outcomes in SARS patients treated with corticosteroids and warrants further exploration [98, 99]. Psychiatric morbidities, including chronic fatigue syndrome, were also reported in patients who recovered from SARS [100]. Given the strong association between psychiatric conditions, such as depression and chronic fatigue syndrome, and CVD, such as chronic HF and cardiac arrhythmias, the evidence backing long-term CV sequelae of these infections appears compelling [101-104].

The outbreak of the pandemic has led to the preservation of medical resources, in terms of hospital beds, medical personnel, and PPE, that have prioritized the care of COVID-19 patients. This has led to stratification and deferral of elective procedures, including structural and electrophysiology procedures [105]. A recent study reported the decrease in cardiac catheterization/percutaneous intervention due to this shift in management protocol [106], resulting in pharmacological management as the alternative. Telemedicine and teleconsultations are being implemented widely. As a result, there has been an unanticipated increase in urgent cases that occur while patients wait for their procedures. In addition, due to a fear of going to the hospital and contracting COVID, it appears many patients may have ignored important symptoms while at home, resulting in a large number of deaths indirectly related to the pandemic. This is

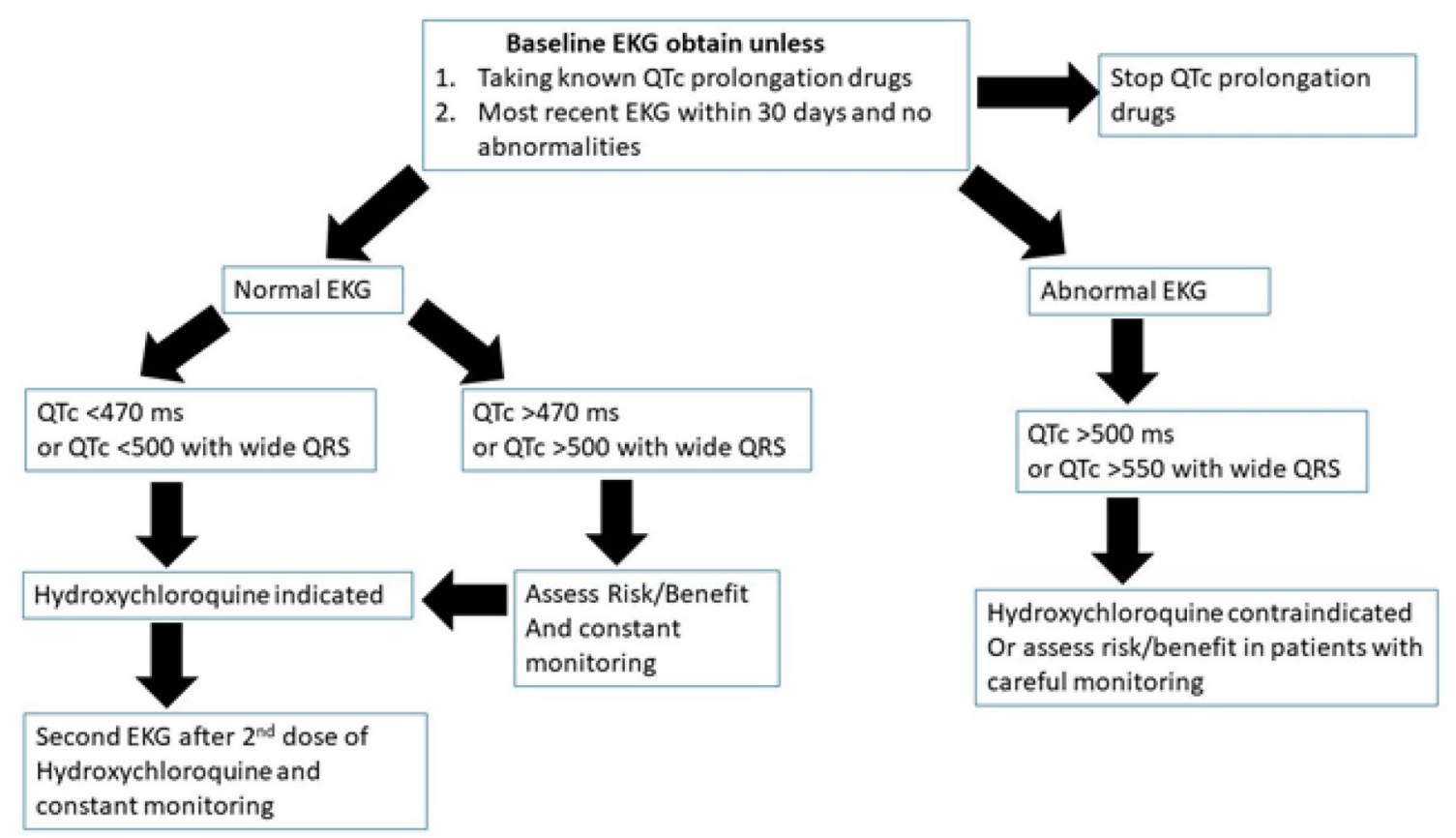

Fig. 3 Workflow for hydroxychloroquine therapy in COVID-19 patients 
Table 3 Treatment modalities used in CoVID-19 and CV adverse effects

\begin{tabular}{|c|c|c|}
\hline Therapy & Rationale in CoVID-19 patients & Cardiovascular adverse effects \\
\hline Chloroquine and hydroxychloroquine & $\begin{array}{l}\text { 1. Inhibits the viral entry through endosomal } \\
\text { trafficking } \\
\text { 2. Immunomodulatory effect through cytokine } \\
\text { attenuation }\end{array}$ & $\begin{array}{l}\text { QTc prolongation, bundle branch block, AV block, } \\
\text { ventricular arrhythmias, Torsades de pointe }\end{array}$ \\
\hline Lopinavir/ritonavir & $\begin{array}{l}\text { Lopinavir inhibits viral protease } \\
\text { Ritonavir inhibits CYP3A metabolism, increasing } \\
\text { the half-life of lopinavir }\end{array}$ & Conduction abnormalities \\
\hline Remdesivir & Viral RNA polymerase inhibitor & No serious cardiac adverse effects \\
\hline Ribavirin & Inhibits viral RNA and DNA replication & Hemolytic anemia \\
\hline Corticosteroids & Anti-inflammatory & Electrolyte imbalance and hypertension \\
\hline Anticytokine agents (tocilizumab) & Inhibits IL-6 and cytokine storm & Rare hypertension \\
\hline Immunoglobulin therapy & $\begin{array}{l}\text { Antibodies against the virus in the convalescent } \\
\text { plasma }\end{array}$ & $\begin{array}{l}\text { Transfusion-related acute lung injury leading to } \\
\text { cardiopulmonary failure }\end{array}$ \\
\hline Low-molecular-weight heparin & Anticoagulation & $\begin{array}{l}\text { Bleeding in the cerebrovascular space, heparin- } \\
\text { induced thrombocytopenia, deep vein thrombo- } \\
\text { sis, and pulmonary embolism }\end{array}$ \\
\hline Extracorporeal membrane oxygenation & $\begin{array}{l}\text { Assisted extracorporeal circulation and physi- } \\
\text { ologic gas exchange in cardiopulmonary failure }\end{array}$ & Distal ischemia and thrombosis \\
\hline Mechanical ventilation & $\begin{array}{l}\text { Assist spontaneous breathing in CoVID-19-in- } \\
\text { duced ARDS }\end{array}$ & $\begin{array}{l}\text { Decreased cardiac output, respiratory alkalosis, } \\
\text { increased intracranial pressure }\end{array}$ \\
\hline
\end{tabular}

$A R D S$ acute respiratory distress syndrome, $A V$ atrioventricular, $C Y P$ cytochrome $\mathrm{P} 450, I L$ interleukin

particularly true for the incidence of STEMI, which showed a sharp decline during the pandemic, paralleling a similar sharp rise in patient deaths at home [107]. Clearly, such an anticipated consequence of our response to pandemics must be mitigated in the future.

A surge of elective procedures is expected after this pandemic, and potentially an increased number of decompensated patients secondary to non-compliance, delayed elective procedures, and completed or late-presenting MI. A recent analysis showed a $38 \%$ decrease in primary PCI in the US during the COVID-19 pandemic, which is partly attributable to avoiding going to the hospital early for fear of contracting the infection in the hospital, misdiagnosis of STEMI, and more use of fibrinolysis [106]. This would likely lead to an increase in the number of post-MI complications, such as mechanical complications, cardiogenic shock, cardiac rupture, post-MI angina, and reinfarction, that were not common previously because of prompt management by an invasive strategy. Some of these complications may not have presented due to deaths at home. Similarly, a significant decrease in ACS-related hospitalization rates across northern Italy has been noted [108]. Interestingly, the incidence of out-of-hospital cardiac arrest has increased [109]. Masking of symptoms such as shortness of breath, chest tightness, underlying poor clinical status of patients secondary to COVID, and fear of accessing the health care system may be the cause of such increased incidence.

\section{Conclusion}

As this new pandemic continues to unfurl, a variety of cardiac manifestations have become evident. There is a need for further research to better understand the spectrum of $\mathrm{CV}$ manifestations. Until a vaccine or potentially curative treatment is available, clinicians should be aware of the known cardiac involvement and address this at the outset to attenuate damage. In addition, we must be vigilant about the potential adverse effects and interactions of existing therapies.

\section{Compliance with Ethical Standards}

Funding No external funding was used in the preparation of this manuscript.

Conflict of interest Dr. Gregg C. Fonarow reports research funding from the NIH and serving as a consultant for Abbott, Amgen, AstraZeneca, Bayer, CHF Solutions, Janssen, Medtronic, Merck, and Novartis. Dhrubajyoti Bandyopadhyay, Tauseef Akhtar, Adrija Hajra, Manasvi Gupta, Avash Das, Sandipan Chakraborty, Ipsita Pal, Neelkumar Patel, Birendra Amgai, Raktim K. Ghosh, Carl J. Lavie, and Srihari S. Naidu declare they have no potential conflicts of interest that might be relevant to the contents of this article.

\section{References}

1. Lu R, Zhao X, Li J, Niu P, Yang B, Wu H, et al. Genomic characterisation and epidemiology of 2019 novel coronavirus: 
implications for virus origins and receptor binding. Lancet. 2020;395(10224):565-74.

2. Callaway E, Cyranoski D, Mallapaty S, Stoye E, Tollefson $\mathrm{J}$. The coronavirus pandemic in five powerful charts. Nature. 2020;579(7800):482-3.

3. Centers for Disease Control and Prevention. Cases in the US. https://www.cdc.gov/coronavirus/2019-ncov/cases-updates/ cases-in-us.html?CDC_AA_refVal=https $\% 3 \mathrm{~A} \% 2 \mathrm{~F} \% 2 \mathrm{Fwww}$ .cdc.gov\%2Fcoronavirus\%2F2019-ncov\%2Fcases-in-us.html. Accessed 29 May 2020

4. Zhang H, Penninger JM, Li Y, Zhong N, Slutsky AS. Angiotensin-converting enzyme 2 (ACE2) as a SARS-CoV-2 receptor: molecular mechanisms and potential therapeutic target. Intensive Care Med. 2020;46(4):586-90.

5. Tortorici MA, Veesler D. Structural insights into coronavirus entry. Adv Virus Res. 2019;105:93-116.

6. Xia S, Zhu Y, Liu M, Lan Q, Xu W, Wu Y, et al. Fusion mechanism of 2019-nCoV and fusion inhibitors targeting HR1 domain in spike protein. Cell Mol Immunol. 2020. https://doi. org/10.1038/s41423-020-0374-2.

7. de Wilde AH, Snijder EJ, Kikkert M, van Hemert MJ. Host factors in coronavirus replication. Curr Top Microbiol Immunol. 2018;419:1-42.

8. Sawicki SG, Sawicki DL. Coronavirus transcription: a perspective. Curr Top Microbiol Immunol. 2005;287:31-55.

9. Belkaid Y, Rouse BT. Natural regulatory T cells in infectious disease. Nat Immunol. 2005;6(4):353-60.

10. Channappanavar R, Perlman S. Pathogenic human coronavirus infections: causes and consequences of cytokine storm and immunopathology. Semin Immunopathol. 2017;39(5):529-39.

11. Siddiqi HK, Mehra MR. COVID-19 illness in native and immunosuppressed states: a clinical-therapeutic staging proposal. J Heart Lung Transplant. 2020;39(5):405-7.

12. Dong E, Du H, Gardner L. An interactive web-based dashboard to track COVID-19 in real time. Lancet Infect Dis. 2020;20(5):533-4.

13. Huang C, Wang Y, Li X, Ren L, Zhao J, Hu Y, et al. Clinical features of patients infected with 2019 novel coronavirus in Wuhan, China. Lancet. 2020;395(10223):497-506.

14. Mehta P, McAuley DF, Brown M, Sanchez E, Tattersall RS, Manson JJ, et al. COVID-19: consider cytokine storm syndromes and immunosuppression. Lancet. 2020;395(10229):1033-4.

15. Ruan Q, Yang K, Wang W, Jiang L, Song J. Clinical predictors of mortality due to COVID-19 based on an analysis of data of 150 patients from Wuhan, China [published erratum appears in Intensive Care Med. Epub 6 Apr 2020]. Intensive Care Med. 2020;46(5):846-8.

16. Wang D, Hu B, Hu C, Zhu F, Liu X, Zhang J, et al. Clinical characteristics of 138 hospitalized patients with 2019 novel coronavirus-infected pneumonia in Wuhan, China. JAMA. 2020;323(11):1061-9.

17. Zhou F, Yu T, Du R, Fan G, Liu Y, Liu Z, et al. Clinical course and risk factors for mortality of adult inpatients with COVID19 in Wuhan, China: a retrospective cohort study. Lancet. 2020;395(10229):1054-62.

18. Guo T, Fan Y, Chen M, Wu X, Zhang L, He T, Wang H, Wan J, Wang X, Lu Z. Cardiovascular implications of fatal outcomes of patients with coronavirus disease 2019 (COVID-19). JAMA Cardiol. 2019. https://doi.org/10.1001/jamacardio.2020.1017.

19. Chen L, Li X, Chen M, Feng Y, Xiong C. The ACE2 expression in human heart indicates new potential mechanism of heart injury among patients infected with SARS-CoV-2. Cardiovasc Res. 2020;116(6):1097-100.

20. Oudit GY, Kassiri Z, Jiang C, Liu PP, Poutanen SM, Penninger JM, et al. SARScoronavirus modulation of myocardial ACE2 expression and inflammation in patients with SARS. Eur J Clin Invest. 2009;39(7):618-25.

21. Lauer SA, Grantz KH, Bi Q, Jones FK, Zheng Q, Meredith HR, et al. The incubation period of coronavirus disease 2019 (COVID-19) from publicly reported confirmed cases: estimation and application. Ann Intern Med. 2020;172(9):577-82.

22. Jin X, Lian JS, Hu JH, Gao J, Zheng L, Zhang YM, et al. Epidemiological, clinical and virological characteristics of 74 cases of coronavirus-infected disease 2019 (COVID-19) with gastrointestinal symptoms. Gut. 2020;69(6):1002-9.

23. Lechien JR, Chiesa-Estomba CM, De Siati DR, Horoi M, Le Bon SD, Rodriguez A, et al. Olfactory and gustatory dysfunctions as a clinical presentation of mild-to-moderate forms of the coronavirus disease (COVID-19): a multicenter European study. Eur Arch Otorhinolaryngol. 2020. https://doi.org/10.1007/s0040 5-020-05965-1.

24. Shi S, Qin M, Shen B, et al. Association of cardiac injury with mortality in hospitalized patients with COVID-19 in Wuhan, China. JAMA Cardiol. 2020. https://doi.org/10.1001/jamacardio .2020.0950.

25. Liu K, Fang YY, Deng Y, Liu W, Wang MF, Ma JP, et al. Clinical characteristics of novel coronavirus cases in tertiary hospitals in Hubei Province. Chin Med J (Engl). 2020;133(9):1025-31. https ://doi.org/10.1097/CM9.0000000000000744.

26. Kwong JC, Schwartz KL, Campitelli MA, Chung H, Crowcroft NS, Karnauchow T, et al. Acute myocardial infarction after laboratory-confirmed influenza infection. N Engl J Med. 2018;378(4):345-53.

27. Bandyopadhyay D, Ashish K, Ghosh S, Hajra A, Modi VA. Cardiovascular implications of Zika virus infection. Eur J Intern Med. 2018;52:e35-e3636.

28. Yu CM, Wong RS, Wu EB, Kong SL, Wong J, Yip GW, et al. Cardiovascular complications of severe acute respiratory syndrome. Postgrad Med J. 2006;82(964):140-4.

29. Li B, Yang J, Zhao F, Zhi L, Wang X, Liu L, Bi Z, Zhao Y. Prevalence and impact of cardiovascular metabolic diseases on COVID-19 in China. Clin Res Cardiol. 2020;109(5):531-8.

30. Chen N, Zhou M, Dong X, Qu J, Gong F, Han Y, et al. Epidemiological and clinical characteristics of 99 cases of 2019 novel coronavirus pneumonia in Wuhan, China: a descriptive study. Lancet. 2020;395(10223):507-13.

31. Zhang JJ, Dong X, Cao YY, Yuan YD, Yang YB, Yan YQ, et al. Clinical characteristics of 140 patients infected with SARS-CoV-2 in Wuhan, China. Allergy. 2020. https://doi.org/10.1111/all.14238.

32. Wang L, He W, Yu X, Hu D, Bao M, Liu H, Zhou J, Jiang H. Coronavirus disease 2019 in elderly patients: characteristics and prognostic factors based on 4-week follow-up. J Infect. 2020;80(6):639-45.

33. Wu J, Li W, Shi X, Chen Z, Jiang B, Liu J, et al. Early antiviral treatment contributes to alleviate the severity and improve the prognosis of patients with novel coronavirus disease (COVID19). J Intern Med. 2020. https://doi.org/10.1111/joim.13063.

34. Chen T, Wu D, Chen H, Yan W, Yang D, Chen G, et al. Clinical characteristics of 113 deceased patients with coronavirus disease 2019: retrospective study. BMJ. 2020;368:m1091.

35. Liang WH, Guan WJ, Li CC, et al. Clinical characteristics and outcomes of hospitalised patients with COVID-19 treated in Hubei (epicenter) and outside Hubei (non-epicenter): a Nationwide Analysis of China. Eur Respir J. 2020;55(6):2000562.

36. McMichael TM, Currie DW, Clark S, Pogosjans S, Kay M, Schwartz NG, et al. Epidemiology of Covid-19 in a longterm care facility in King County, Washington. N Engl J Med. 2020;382(21):2005-111.

37. Cao J, Tu WJ, Cheng W, Yu L, Liu YK, Hu X, et al. Clinical features and short-term outcomes of 102 patients with corona 
virus disease 2019 in Wuhan, China. Clin Infect Dis. 2020. https ://doi.org/10.1093/cid/ciaa243.

38. Shao F, Xu S, Ma X, Xu Z, Lyu J, Ng M, et al. In-hospital cardiac arrest outcomes among patients with COVID-19 pneumonia in Wuhan, China. Resuscitation. 2020;151:18-23.

39. Richardson S, Hirsch JS, Narasimhan M, Crawford JM, McGinn T, Davidson KW, et al. Presenting characteristics, comorbidities, and outcomes among 5700 patients hospitalized with COVID-19 in the New York City area. JAMA. 2020;323(20):2052-9.

40. Goyal P, Choi JJ, Pinheiro LC, Schenck EJ, Chen R, Jabri A, et al. Clinical characteristics of Covid-19 in New York City. N Engl J Med. 2020. https://doi.org/10.1056/NEJMc2010419.

41. Grasselli G, Zangrillo A, Zanella A, Antonelli M, Cabrini L, Castelli A, et al. Baseline characteristics and outcomes of 1591 patients infected with SARS-CoV-2 admitted to ICUs of the Lombardy Region, Italy. JAMA. 2020;323(16):1574-81.

42. Tersalvi G, Vicenzi M, Calabretta D, Biasco L, Pedrazzini G, Winterton D. Elevated troponin in patients with Coronavirus Disease 2019 (COVID-19): possible mechanisms. J Card Fail. 2020. https://doi.org/10.1016/j.cardfail.2020.04.009.

43. Yao XH, Li TY, He ZC, Ping YF, Liu HW, Yu SC, et al. A pathological report of three COVID-19 cases by minimally invasive autopsies. Chin J Pathol. 2020;49(5):411-7.

44. Long B, Brady WJ, Koyfman A, Gottlieb M. Cardiovascular complications in COVID-19. Am J Emerg Med. 2020. https:// doi.org/10.1016/j.ajem.2020.04.048.

45. Rivara MB, Bajwa EK, Januzzi JL, Gong MN, Thompson BT, Christiani DC. Prognostic significance of elevated cardiac troponin-T levels in acute respiratory distress syndrome patients. PLoS ONE. 2012;7(7):e40515.

46. Bajwa EK, Boyce PD, Januzzi JL, Gong MN, Thompson BT, Christiani DC. Biomarker evidence of myocardial cell injury is associated with mortality in acute respiratory distress syndrome. Crit Care Med. 2007;35(11):2484-90.

47. Du RH, Liang LR, Yang CQ, Wang W, Cao TZ, Li M, et al. Predictors of mortality for patients with COVID-19 pneumonia caused by SARS-CoV-2: a prospective cohort study. Eur Respir J. 2020;55(5):2000524.

48. Han H, Xie L, Liu R, Yang J, Liu F, Wu K, et al. Analysis of heart injury laboratory parameters in 273 COVID-19 patients in one hospital in Wuhan, China. J Med Virol. 2020. https://doi. org/10.1002/jmv.25809.

49. Deng Q, Hu B, Zhang Y, Wang H, Zhou X, Hu W, et al. Suspected myocardial injury in patients with COVID-19: evidence from front-line clinical observation in Wuhan, China. Int J Cardiol. 2020;311:116-21.

50. Zhou B, She J, Wang Y, Ma X. The clinical characteristics of myocardial injury in severe and very severe patients with 2019 novel coronavirus disease. J Infect. 2020. https://doi. org/10.1016/j.jinf.2020.03.021.

51. Li JW, Han TW, Woodward M, Anderson CS, Zhou H, Chen YD, Neal B. The impact of novel coronavirus on heart injury: a systematic review and meta-analysis. Prog Cardiovasc Dis. 2020. https://doi.org/10.1016/j.pcad.2020.04.008.

52. Lippi G, Lavie CJ, Sanchis-Gomar F. Cardiac troponin I in patients with coronavirus disease 2019 (COVID-19): evidence from a meta-analysis. Prog Cardiovasc Dis. 2020. https://doi. org/10.1016/j.pcad.2020.03.001.

53. Zeng JH, Liu YX, Yuan J, Wang FX, Wu WB, Li JX, et al. First case of COVID-19 complicated with fulminant myocarditis: a case report and insights. Infection. 2020. https://doi.org/10.1007/ s15010-020-01424-5.

54. Hua A, O'Gallagher K, Sado D, Byrne J. Life-threatening cardiac tamponade complicating myo-pericarditis in COVID-19. Eur Heart J. 2020. https://doi.org/10.1093/eurheartj/ehaa253.
55. Dabbagh MF, D'Souza P, Weinmann AJ, Bhargava P, Basir MB. Cardiac Tamponade Secondary to COVID-19. JACC Case Rep. 2020. https://doi.org/10.1016/j.jaccas.2020.04.009.

56. Meyer P, Degrauwe S, Van Delden C, Ghadri JR, Templin C. Typical Takotsubo syndrome triggered by SARS-CoV-2 infection. Eur Heart J. 2020;41(19):1860.

57. Minhas AS, Scheel P, Garibaldi B, Liu G, Horton M, Jennings M, Jones SR, Michos ED, Hays AG. Takotsubo Syndrome in the Setting of COVID-19 Infection. JACC Case Rep. 2020. https:// doi.org/10.1016/j.jaccas.2020.04.023.

58. Harikrishnan S, Mohanan PP, Chopra VK, Ambuj R, Sanjay G, Manish B, et al. Cardiological society of India position statement on COVID-19 and heart failure. Indian Heart J. 2020. https://doi. org/10.1016/j.ihj.2020.04.012.

59. Tam CF, Cheung KS, Lam S, Wong A, Yung A, Sze M, et al. Impact of coronavirus disease 2019 (COVID-19) outbreak on STSegment-Elevation Myocardial Infarction Care in Hong Kong, China. Circ Cardiovasc Qual Outcomes. 2020;13(4):e006631.

60. Park J, Choi KH, Lee JM, Kim HK, Hwang D, Rhee TM, et al. Prognostic implications of door-to-balloon time and onset-todoor time on mortality in patients with ST-segment-elevation myocardial infarction treated with primary percutaneous coronary intervention. J Am Heart Assoc. 2019;8(9):e012188.

61. Welt FGP, Shah PB, Aronow HD, Bortnick AE, Henry TD, Sherwood MW, et al. Catheterization laboratory considerations during the coronavirus (COVID-19) pandemic: from ACC's Interventional Council and SCAI. J Am Coll Cardiol. 2020;75(18):2372-5.

62. Tett S, Cutler D, Day R. Antimalarials in rheumatic diseases. Baillieres Clin Rheumatol. 1990;4(3):467-89.

63. Jones SK. Ocular toxicity and hydroxychloroquine: guidelines for screening. Br J Dermatol. 1999;140(1):3-7.

64. Lakkireddy DR, Chung MK, Gopinathannair R, Patton KK, Gluckman TJ, Turagam M, et al. Guidance for Cardiac Electrophysiology During the Coronavirus (COVID-19) Pandemic from the Heart Rhythm Society COVID-19 Task Force; Electrophysiology Section of the American College of Cardiology; and the Electrocardiography and Arrhythmias Committee of the Council on Clinical Cardiology, American Heart Association. Heart Rhythm. 2020. https://doi.org/10.1016/j.hrthm.2020.03.028.

65. American College of Cardiology. Ventricular arrhythmia risk due to hydroxychloroquine-azithromycin treatment for COVID-19. https://www.acc.org/latest-in-cardiology/artic les/2020/03/27/14/00/ventricular-arrhythmia-risk-due-to-hydro xychloroquine-azithromycin-treatment-for-covid-19. Accessed 18 May 2020.

66. US FDA. FDA cautions against use of hydroxychloroquine or chloroquine for COVID-19 outside of the hospital setting or a clinical trial due to risk of heart rhythm problems. Available online from: https://www.fda.gov/drugs/drug-safety-and-avail ability/fda-cautions-against-use-hydroxychloroquine-or-chlor oquine-covid-19-outside-hospital-setting-or. Accessed 9 June 2020.

67. Edelson DP, Sasson C, Chan PS, Atkins DL, Aziz K, Becker LB, et al. Interim Guidance for Basic and Advanced Life Support in Adults, Children, and Neonates with Suspected or Confirmed COVID-19: From the Emergency Cardiovascular Care Committee and Get with the Guidelines ${ }^{\circledR}$-Resuscitation Adult and Pediatric Task Forces of the American Heart Association in Collaboration with the American Academy of Pediatrics, American Association for Respiratory Care, American College of Emergency Physicians, The Society of Critical Care Anesthesiologists, and American Society of Anesthesiologists Circulation: Supporting Organizations: American Association of Critical Care Nurses and National EMS Physicians. Circulation. 2020. https://doi.org/10.1161/CIRCULATIONAHA.120.047463. 
68. Giannis D, Ziogas IA, Gianni P. Coagulation disorders in coronavirus infected patients: COVID-19, SARS-CoV-1, MERS-CoV and lessons from the past. J Clin Virol. 2020;127:104362.

69. Tang N, Bai H, Chen X, Gong J, Li D, Sun Z. Anticoagulant treatment is associated with decreased mortality in severe coronavirus disease 2019 patients with coagulopathy. J Thromb Haemost. 2020;18(5):1094-9.

70. Panigada M, Bottino N, Tagliabue P, Grasselli G, Novembrino C, Chantarangkul V, et al. Hypercoagulability of COVID-19 patients in Intensive Care Unit. A report of thromboelastography findings and other parameters of hemostasis. J Thromb Haemost. 2020. https://doi.org/10.1111/jth.14850.

71. Klok FA, Kruip M, van der Meer NJM, Arbous MS, Gommers $\mathrm{D}$, Kant KM, et al. Incidence of thrombotic complications in critically ill ICU patients with COVID-19. Thromb Res. 2020. https://doi.org/10.1016/j.thromres.2020.04.013.

72. Rotzinger DC, Beigelman-Aubry C, von Garnier C, Qanadli SD. Pulmonary embolism in patients with COVID-19: Time to change the paradigm of computed tomography. Thromb Res. 2020;190:58-9.

73. Casey K, Iteen A, Nicolini R, Auten J. COVID-19 pneumonia with hemoptysis: acute segmental pulmonary emboli associated with novel coronavirus infection. Am J Emerg Med. 2020. https ://doi.org/10.1016/j.ajem.2020.04.011.

74. Bĕlohlávek J, Dytrych V, Linhart A. Pulmonary embolism, part I: epidemiology, risk factors and risk stratification, pathophysiology, clinical presentation, diagnosis and nonthrombotic pulmonary embolism. Exp Clin Cardiol. 2013;18(2):129.

75. Kollias A, Kyriakoulis KG, Dimakakos E, Poulakou G, Stergiou GS, Syrigos K. Thromboembolic risk and anticoagulant therapy in COVID-19 patients: emerging evidence and call for action. $\mathrm{Br}$ J Haematol. 2020. https://doi.org/10.1111/bjh.16727.

76. Barrett CD, Moore HB, Yaffe MB, Moore EE. ISTH interim guidance on recognition and management of coagulopathy in COVID-19: a comment. J Thromb Haemost. 2020.

77. Thachil J. The versatile heparin in COVID-19. J Thromb Haemost. 2020. https://doi.org/10.1111/jth.14860.

78. Wang J, Hajizadeh N, Moore EE, McIntyre RC, Moore PK, Veress LA, et al. Tissue plasminogen activator (tPA) treatment for COVID-19 associated acute respiratory distress syndrome (ARDS): a case series. J Thromb Haemost. 2020. https://doi. org/10.1111/jth.14828

79. Thachil J, Tang N, Gando S, Falanga A, Cattaneo M, Levi M, et al. DOACs and 'newer' haemophilia therapies in COVID-19. J Thromb Haemost. 2020. https://doi.org/10.1111/jth.14841.

80. Asakura H, Ogawa $\mathrm{H}$. Potential of heparin and nafamostat combination therapy for COVID-19. J Thromb Haemost. 2020. https ://doi.org/10.1111/jth.14858.

81. Llitjos JF, Leclerc M, Chochois C, Monsallier JM, Ramakers $\mathrm{M}$, Auvray M, et al. High incidence of venous thromboembolic events in anticoagulated severe COVID-19 patients. J Thromb Haemost. 2020. https://doi.org/10.1111/jth.14869.

82. Paranjpe I, Fuster V, Lala A, Russak A, Glicksberg BS, Levin MA, Charney AW, Narula J, Fayad ZA, Bagiella E, Zhao S. Association of treatment dose anticoagulation with in-hospital survival among hospitalized patients with COVID-19. J Am Coll Cardiol. 2020. https://doi.org/10.1016/j.jacc.2020.05.001].

83. Yang J, Zheng Y, Gou X, Pu K, Chen Z, Guo Q, et al. Prevalence of comorbidities in the novel Wuhan coronavirus (COVID-19) infection: a systematic review and meta-analysis. Int J Infect Dis. 2020;94:91-5. https://doi.org/10.1016/j.ijid.2020.03.017.

84. Jia X, Yin C, Lu S, Chen Y, Liu Q, Bai J, et al. Two things about COVID-19 might need attention. Preprints. 2020. https://doi. org/10.20944/preprints202002.0315.v1.

85. Danser AHJ, Epstein M, Batlle D. Renin-angiotensin system blockers and the COVID-19 pandemic: at present there is no evidence to abandon renin-angiotensin system blockers. Hypertension. 2020;75(6):1382-5.

86. Zhang P, Zhu L, Cai J, Lei F, Qin JJ, Xie J, et al. Association of inpatient use of angiotensin converting enzyme inhibitors and angiotensin II receptor blockers with mortality among patients with hypertension hospitalized with COVID-19. Circ Res. 2020. https://doi.org/10.1161/CIRCRESAHA.120.317134.

87. Jarcho JA, Ingelfinger JR, Hamel MB, D'Agostino RB Sr, Harrington DP. Inhibitors of the renin-angiotensin-aldosterone system and Covid-19. N Engl J Med. 2020. https://doi.org/10.1056/ NEJMe2012924.

88. Li J, Wang X, Chen J, Zhang H, Deng A. Association of reninangiotensin system inhibitors with severity or risk of death in patients with hypertension hospitalized for coronavirus disease 2019 (COVID-19) infection in Wuhan, China. JAMA Cardiol. 2020. https://doi.org/10.1001/jamacardio.2020.1624.

89. Guo J, Huang Z, Lin L, Lv J. Coronavirus disease 2019 (COVID19) and cardiovascular disease: a viewpoint on the potential influence of angiotensin-converting enzyme inhibitors/angiotensin receptor blockers on onset and severity of severe acute respiratory syndrome coronavirus 2 infection. J Am Heart Assoc. 2020;9(7):e016219.

90. Sanchis-Gomar F, Lavie CJ, Perez-Quilis C, Henry BM, Lippi G. Angiotensin-converting enzyme 2 and antihypertensives (angiotensin receptor blockers and angiotensin-converting enzyme inhibitors) in coronavirus disease 2019. Mayo Clin Proc. 2020. https://doi.org/10.1016/j.mayocp.2020.03.026.

91. Hajra A, Bandyopadhyay D. COVID-19 and ACEI/ARB: not associated? Am J Hypertens. 2020. https://doi.org/10.1093/ajh/ hpaa076.

92. Sanders JM, Monogue ML, Jodlowski TZ, Cutrell JB. pharmacologic treatments for coronavirus disease 2019 (COVID-19): a review. JAMA. 2020;323(18):1824-36.

93. US FDA. Kaletra prescribing information. https://www.acces sdata.fda.gov/drugsatfda_docs/label/2013/021251s046_02190 6s039lbl.pdf. Accessed 18 May 2020.

94. Al-Tawfiq JA, Al-Homoud AH, Memish ZA. Remdesivir as a possible therapeutic option for the COVID-19. Travel Med Infect Dis. 2020;34:101615.

95. Altered Lipid Metabolism in Recovered SARS Patients Twelve Years after Infection. Scientific Reports. https://www.natur e.com/articles/s41598-017-09536-z. Accessed 15 Apr 2020.

96. Hong N, Du XK. Avascular necrosis of bone in severe acute respiratory syndrome. Clin Radiol. 2004;59(7):602-8.

97. Zhang P, Li J, Liu H, Han N, Ju J, Kou Y, et al. Long-term bone and lung consequences associated with hospital-acquired severe acute respiratory syndrome: a 15-year follow-up from a prospective cohort study. Bone Res. 2020;8:8.

98. Sung PH, Yang YH, Chiang HJ, Chiang JY, Chen CJ, Yip HK, et al. Cardiovascular and cerebrovascular events are associated with nontraumatic osteonecrosis of the femoral head. Clin Orthop Relat Res. 2018;476(4):865-74.

99. Kang JH, Lin HC. Increased risk for coronary heart disease after avascular necrosis of femoral head: a 3-year follow-up study. Am Heart J. 2010;159(5):803-808e1.

100. Lam MH, Wing YK, Yu MW, Leung CM, Ma RC, Kong AP, et al. Mental morbidities and chronic fatigue in severe acute respiratory syndrome survivors: long-term follow-up. Arch Intern Med. 2009;169(22):2142-7.

101. Das A, Roy B, Schwarzer G, Silverman MG, Ziegler O, Bandyopadhyay D, et al. Comparison of treatment options for depression in heart failure: a network meta-analysis. J Psychiatr Res. 2019;108:7-23.

102. Patel N, Chakraborty S, Bandyopadhyay D, Amgai B, Hajra A, Atti V, et al. Association between depression and readmission of heart failure: a national representative database 
study. Prog Cardiovasc Dis. 2020. https://doi.org/10.1016/j. pcad.2020.03.014.

103. De Hert M, Detraux J, Vancampfort D. The intriguing relationship between coronary heart disease and mental disorders. Dialogues Clin Neurosci. 2018;20(1):31-40.

104. Bozzini S, Albergati A, Capelli E, Lorusso L, Gazzaruso C, Pelissero G, et al. Cardiovascular characteristics of chronic fatigue syndrome. Biomed Rep. 2018;8(1):26-30.

105. Stahel PF. How to risk-stratify elective surgery during the COVID-19 pandemic? Patient Saf Surg. 2020;14:8.

106. Garcia S, Albaghdadi MS, Meraj PM, Schmidt C, Garberich $\mathrm{R}$, Jaffer FA, et al. Reduction in ST-segment elevation cardiac catheterization laboratory activations in the United States during
COVID-19 pandemic. J Am Coll Cardiol. 2020. https://doi. org/10.1016/j.jacc.2020.04.011.

107. Zitelny E, Newman N, Zhao D. STEMI during the COVID19 pandemic: an evaluation of incidence. Cardiovasc Pathol. 2020;48:107232.

108. De Filippo O, D’Ascenzo F, Angelini F, Bocchino PP, Conrotto F, Saglietto A, et al. Reduced rate of hospital admissions for ACS during Covid-19 outbreak in Northern Italy. N Engl J Med. 2020. https://doi.org/10.1056/NEJMc2009166.

109. Baldi E, Sechi GM, Mare C, Canevari F, Brancaglione A, Primi $\mathrm{R}$, et al. Out-of-hospital cardiac arrest during the Covid-19 outbreak in Italy. N Engl J Med. 2020. https://doi.org/10.1056/ NEJMc2010418.

\section{Affiliations}

\section{Dhrubajyoti Bandyopadhyay ${ }^{1} \cdot$ Tauseef Akhtar $^{2} \cdot$ Adrija Hajra $^{3}$ (D) Manasvi Gupta ${ }^{4} \cdot$ Avash Das $^{5}$. Sandipan Chakraborty ${ }^{6} \cdot$ Ipsita Pal $^{7} \cdot$ Neelkumar Patel $^{8} \cdot$ Birendra Amgai $^{8} \cdot$ Raktim K. Ghosh $^{9} \cdot$ Gregg C. Fonarow $^{10}$. Carl J. Lavie ${ }^{11}$. Srihari S. Naidu ${ }^{12}$}

Dhrubajyoti Bandyopadhyay

dhrubajyoti.bandyopadhyay@mountsinai.org

Tauseef Akhtar

tausif.akhtar@gmail.com

Manasvi Gupta

manasvi.gupta.93@gmail.com

Avash Das

avash.nrs@gmail.com

Sandipan Chakraborty

schakraborty591@gmail.com

Ipsita Pal

ipsita.pal1984@gmail.com

Neelkumar Patel

neelpatel.ny@gmail.com

Birendra Amgai

biren.amgai08@gmail.com

Raktim K. Ghosh

raktimghoshmd@gmail.com

Gregg C. Fonarow

GFonarow@mednet.ucla.edu

Carl J. Lavie

clavie@ochsner.org

Srihari S. Naidu

Srihari.Naidu@wmchealth.org
1 Icahn School of Medicine at Mount Sinai/Mount Sinai St Luke's Roosevelt Hospital, Manhattan, NY, USA

2 John's Hopkins University School of Medicine, Baltimore, MD, USA

3 Jacobi Medical Center/Albert Einstein College of Medicine, Bronx, NY, USA

4 University of Connecticut School of Medicine, Hartford, CT, USA

5 University of Texas Southwestern Medical Center, Dallas, TX, USA

6 Miami Valley Hospital, Columbus, OH, USA

7 Columbia University Irving Medical Center, New York, NY, USA

8 Interfaith Medical Center, Brooklyn, NY, USA

9 Medstar Union Memorial Hospital, Baltimore, MD, USA

10 Ahmanson-UCLA Cardiomyopathy Center, Ronald Reagan-UCLA Medical Center, Los Angeles, CA, USA

11 John Ochsner Heart and Vascular Institute, Ochsner Clinical School, The University of Queensland School of Medicine, New Orleans, LA, USA

12 Westchester Medical Center, Valhalla, NY, USA 